\title{
Prediction of retinopathy of prematurity using the screening algorithm WINROP in a Saudi cohort of preterm infants
}

Lina H. Raffa, MD, PhD, Sarah K. Alessa, MD, Aliaa S. Alamri, MD, Rawan H. Malaikah, MD.

\begin{abstract}

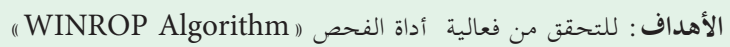

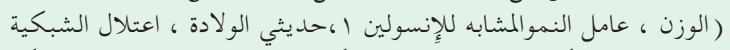

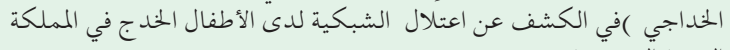

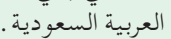

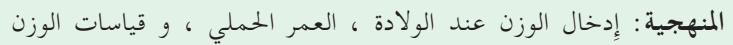

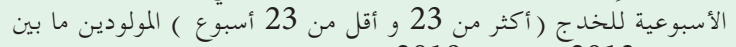

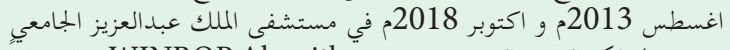

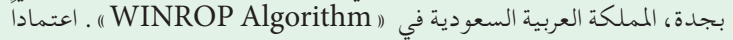

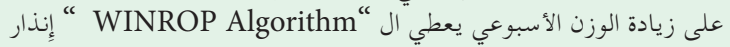

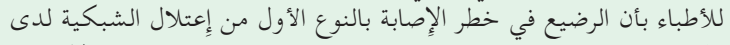

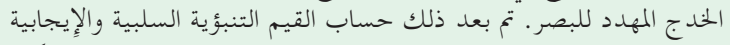
باستخدام حساسية وخصوصية ومعدل انتشار النوع الأول من اعتلال الشبكية لأليكية لدى الحندج

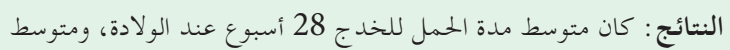

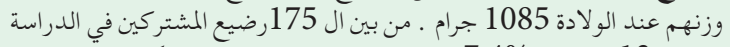

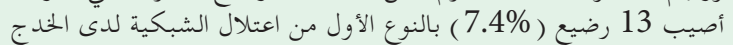

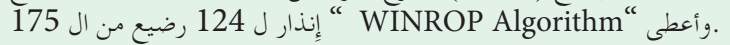

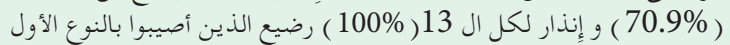

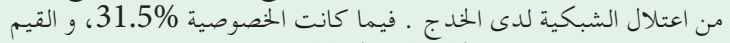
التنبؤية الإيجابية والسلبية 10.5\% و 100\%، على التوالي.

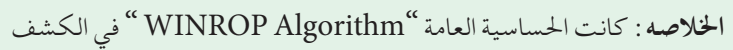

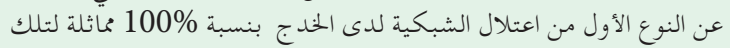

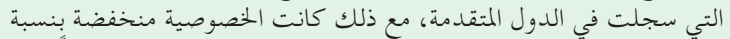

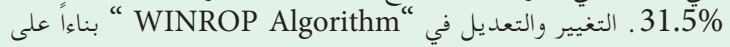

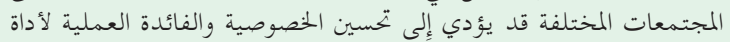
الفحص غير التداخلية لأطباء العيون وأطباء حد يثي الولادة في مجتمعنا.
\end{abstract}

Objectives: To validate the web weight gainbased WINROP (weight, insulin-like growth factor I, neonatal, retinopathy of prematurity [ROP]) algorithm retrospectively to identify type 1 ROP in a Saudi cohort of premature infants.

Methods: The records of preterm infants ( $>23$ and $<32$ weeks gestation) born between August 2013 and October 2018, were reviewed. Birth weight, gestational age, and weekly weight measurements of the premature infants were entered online. Based on weekly weight gain, the WINROP algorithm alerted clinicians whether infants were at high-risk for vision-threatening type 1 ROP. Sensitivity, specificity, positive and negative predictive values were calculated.

Results: The median gestational age of the infants at birth was 28 weeks, with median birth weight at $1085 \mathrm{~g}$. Of the 175 infants included in the study, 13 (7.4\%) developed type 1 ROP. WINROP positive alarm was triggered in $70.9 \%$ (124/175) of all infants and $100 \%(13 / 13)$ of those treated for type 1 ROP. The specificity of the algorithm was $31.5 \%$. Positive predictive values was $10.5 \%$ and negative was $100 \%$.

Conclusion: The general WINROP sensitivity in identifying type 1 ROP was $100 \%$ similar to that reported in developed countries; however, its specificity was low at $31.5 \%$. Tweaking of the algorithm based on the population may increase the specificity and promote the practical utility of this non-invasive screening tool for ophthalmologists and neonatologists in this population.

Keywords: birth weight, gestational age, IGF-1, weight gain, Saudi Arabia

Saudi Med J 2020; Vol. 41 (6): 622-627

doi: 10.15537/smj.2020.6.25127

From the Department of Ophthalmology (Raffa, Malaikah) and from the Faculty of Medicine (Alessa, Alamri), King Abdulaziz University, Jeddah, Kingdom of Saudi Arabia.

Received 17th March 2020. Accepted 19th May 2020.

Address correspondence and reprint request to: Dr. Lina Raffa, Department of Ophthalmology, King Abdulaziz University Hospital, Jeddah, Kingdom of Saudi Arabia. E-mail: lraffa@kau.med.sa ORCID ID: https://orcid.org/0000-0001-8211-2353 
$\mathrm{R}_{\mathrm{s}}$ etinopathy of prematurity (ROP) is a visionthreatening vascular proliferative disorder among the preterm infant population. ${ }^{1}$ The frequency of ROP based on the Cryotherapy for Retinopathy of Prematurity Cooperative Group is estimated to occur in $66 \%$ of infants under $1,250 \mathrm{~g}$, reaching up to $82 \%$ among infants under 1000 g. $^{2}$ Retinopathy of prematurity should be effectively and quickly detected because, if left untreated, it can lead to visual impairment or even vision loss. ${ }^{3}$ The effective screening program should identify infants with ROP that require treatment. Currently, the gold standard test for the diagnosis of ROP is ophthalmological examination, but it is a stressful and painful procedure. ${ }^{4}$ In contrast, the WINROP algorithm (weight, insulin-like growth factor [IGF], neonatal, ROP) is a non-invasive, simple, and inexpensive method of predicting ROP risk..$^{5,6}$

The online WINROP algorithm ${ }^{7}$ can be used to identify infants with an increased risk for severe ROP. ${ }^{5,6}$ It was developed in Gothenburg, Sweden based on their studies of IGF-1 showing a correlation between a prolonged period of low-level serum IGF-1 and ROP. ${ }^{5,6}$ WINROP, calculated based on birth weight $(\mathrm{BW})$, postnatal weight gain, and gestational age (GA) determines the approximate IGF-1 levels and, in this way, identifies the risk for vision-threatening ROP., ${ }^{5,6}$

The WINROP surveillance system has been validated in several studies. ${ }^{8-12}$ In highly developed countries (Sweden and United States), ${ }^{5,13}$ the accuracy of the test was higher, as opposed to that in less and moderately developed countries (Taiwan, Turkey, Korea). ${ }^{14-16}$ This study aims to retrospectively validate the diagnostic accuracy of the readily available online WINROP algorithm in the detection of vision-threatening type $1 \mathrm{ROP}$ in a cohort of premature infants from Jeddah, Saudi Arabia.

Methods. The study included preterm infants from the Neonatal Intensive Care Unit of a tertiary university hospital in Jeddah, Saudi Arabia born between August 2013 and October 2018. All infants who underwent screening for ROP, had their weight measured every week, and had survived the final ophthalmologic ROP assessment were included. Exclusion criteria were gestational age at delivery $<23$ or $>31+6$ weeks' gestation, incomplete weight entry, and no final ROP

Disclosure. Authors have no conflict of interests, and the work was not supported or funded by any drug company. outcome documentation. Ethical clearance for the study was given by the Hospital's Research Ethics Committee, which also conformed to the Declaration of Helsinki.

Infants demographics, GA, BW, and serial weight measurements were noted. In our center, infants were weighed every day until discharge. Each weekly weight had been entered into WINROP measured at exactly 1,2 , and 3 weeks, and so forth, after the child's birth date. Also documented were the infant's worst stage of ROP in either eye, ROP zone, presence/absence of plus disease, and ROP treatment.

Retinopathy of prematurity screening. At our institute, infants who were eligible for ROP examination, according to the American Academy of Pediatrics guidelines, ${ }^{17}$ were examined by pediatric ophthalmologists or vitreoretinal surgeons and categorized following the International Classification of ROP. ${ }^{18}$ All treatments were administered following the Early Treatment for Retinopathy of Prematurity Study guidelines. ${ }^{19}$ Retinopathy of prematurity screening was continued until treatment was required or complete vascularization of the retina occurred.

WINROP screening. Based on weekly weight gain, the WINROP algorithm alerted clinicians whether infants were at risk for vision-threatening type 1 ROP. ${ }^{20}$ Data entered into the WINROP algorithm included BW, GA, and weekly weight measurements until an alarm was signaled or a corrected gestational age of 35-36 weeks was reached.

The WINROP program categorizes infants into 2 groups: positive alarm and no alarm. An alarm identifies infants who are at high risk for type 1 ROP requiring treatment (based on the ETDRS guidelines). Alarm timing was recorded for all infants, and an infant was labeled to be at minimal risk for developing type $1 \mathrm{ROP}$ (non-type 1 ROP) if no alarm was signaled by the time the initial ROP examination was performed. When the accumulated differences between the expected postnatal weight gain and the expected preset values, taking into account the BW and GA at birth, is exceeded, the alarm is signaled.

Statistical analysis. The study data was analyzed using IBM SPSS Statistics for Windows version 23 (IBM Corp., Armonk, N.Y., USA). Quantitative variables were expressed as mean \pm standard deviation (SD) or median \pm interquartile range, whereas qualitative variables are presented as numbers and percentages. Fisher's exact test and Chi-square tests were used to check if there is a difference between categorical variables. While comparing 2 group means, an Independent t-test was used. These tests were carried out with the assumption of normal distribution. Sensitivity and specificity 
of WINROP alarm in predicting type 1 ROP were calculated based on actual ROP outcomes. Prevalence of type $1 \mathrm{ROP}$ in the cohort was further used to calculate positive and negative predictive values of WINROP. Confidence intervals (CIs) were constructed at a $95 \%$ confidence level. The results of the ophthalmologic examination were adopted as the "gold standard". In addition, the level of accuracy between the WINROP algorithm results and the final diagnosis were calculated using Cohen's kappa coefficient $\kappa$. In all analyses, the differences were defined as significant when the $\mathrm{p}$-value was less than 0.05 .

Results. Retinopathy of prematurity screening was carried out for a total of 297 infants during the study period. Ninety-one were excluded for lack of weekly entry of weight measurements. Five were excluded due to missing data, and 26 for being $<23$ weeks or $>32$ weeks GA. Overall, 175 infants were included. Median BW was $1085 \mathrm{~g}$ (552-1920 g) and GA was 28 weeks (23-31 weeks). Among the 175 screened, none developed stage 4 or higher ROP. Sixty-eight patients (38.9\%) developed any grade of ROP (non-type 1 ROP) and 13 infants $(19.1 \%)$ developed vision-threatening type 1 ROP requiring treatment based on ophthalmic assessment.

WINROP outcome. Among the 175 screened, no alarm was triggered in 51 infants $(29.1 \%)$. Of those, none developed type 1 ROP. The median BW in these infants was $1300 \mathrm{~g}$ (range, 792-1920 g) and GA was 29 weeks (range, 24-31 weeks). A positive alarm was triggered in 124 infants (70.9\%). Of these, 13 developed type 1 ROP. The median BW in this cohort was 986.5 $\mathrm{g}$ (range, 552-1380 g) and GA was 28 weeks (range, 23-31 weeks) (Table 1). The mean time from the alarm alert to start of treatment was $4.83 \pm 3.7$ weeks.

Retinopathy of prematurity outcome versus WINROP algorithm (test characteristics). The WINROP algorithm sensitivity in detecting ROP requiring treatment was $100 \%$, with a specificity of $31.5 \%$. Positive predictive value was $10.5 \%$ and negative was $100.0 \%$ (Table 2). The algorithm identified $13 / 13$ infants who required treatment but missed 12 infants who developed any stage of ROP in whom no alarm was signaled on WINROP. The mean age at detection of ROP was $29.83 \pm 1.6$ weeks corrected gestational age. The accuracy rate of the WINROP algorithm was calculated to be $36.6 \%$. Using WINROP, ROP screening could have been reduced by $29.1 \%(51 / 175)$ in our sample based on the number of infants who did not signal an alarm and who turned out non-type 1 ROPs.

The weekly weight curve of infants developing any stage of ROP and whom the WINROP algorithm did not identify as high-risk with respect to other infants is shown in Figure 1. Infants with type 1 ROP had a significantly lower weight than those with non-type 1 ROP or the missed patients (those who did not signal an alarm but developed any stage ROP).

Discussion. It would be helpful for clinicians to screen and prevent ROP if they could identify postnatal factors that may potentially affect ROP severity. Based on clinical studies, an association exists between the

Table 1 - Relationship of WINROP alarm signal to case characteristics and ROP stage.

\begin{tabular}{|c|c|c|c|}
\hline \multirow[t]{2}{*}{ Variables } & \multicolumn{2}{|c|}{ WINROP alarm } & \multirow[t]{2}{*}{$P$-value } \\
\hline & $\begin{array}{l}\text { No alarm } \\
(\mathrm{n}=51)\end{array}$ & $\begin{array}{l}\text { Positive alarm } \\
\quad(\mathrm{n}=124)\end{array}$ & \\
\hline GA at birth $($ mean $\pm S D)$ & $29.18 \pm 1.7$ & $27.92 \pm 1.5$ & $<0.001$ \\
\hline Length of NICU stay (days) (mean \pm SD) & $46.76 \pm 34.8$ & $69.12 \pm 37.5$ & $<0.001$ \\
\hline Birth Weight $($ mean \pm SD) & $1336.69 \pm 185.0$ & $973.53 \pm 184.3$ & $<0.001$ \\
\hline GA at discharge (weeks) (mean \pm SD) & $35.86 \pm 4.9$ & $37.82 \pm 5.0$ & 0.018 \\
\hline Birth to alarm time (weeks) (mean $\pm \mathrm{SD}$ ) & $5.29 \pm 1.9$ & $1.91 \pm 1.2$ & $<0.001$ \\
\hline $\begin{array}{l}\text { Worst ROP stage either eye (\%) } \\
\quad \text { Stage } 1\end{array}$ & $12(27.3)$ & $32(72.7)$ & 0.019 \\
\hline Stage 2 & $0(0.0)$ & $14(100.0)$ & \\
\hline Stage 3 & $0(0.0)$ & $10(100.0)$ & \\
\hline $\begin{array}{r}\text { GA: gestational ag } \\
\text { ROP: }\end{array}$ & $\begin{array}{l}\text { CU: neonatal inten } \\
\text { opathy of prematuri }\end{array}$ & care unit, & \\
\hline
\end{tabular}


Table 2 - Sensitivity, specificity, positive and negative predictive value in predicting type 1 ROPs (those requiring treatment) using the WINROP algorithm.

\begin{tabular}{|c|c|c|c|c|c|}
\hline \multirow[t]{2}{*}{ ROP Category } & \multicolumn{3}{|c|}{ Alarm status group } & \multirow{2}{*}{$\begin{array}{r}\text { Sensitivity } \\
(95 \% \text { CI })\end{array}$} & \multirow{2}{*}{$\begin{array}{r}\text { Specificity } \\
(95 \% \mathrm{CI})\end{array}$} \\
\hline & $\begin{array}{c}\text { Positive alarm } \\
\mathrm{n}=124\end{array}$ & $\begin{array}{c}\text { No alarm } \\
\mathrm{n}=51\end{array}$ & $\begin{array}{c}\text { Both } \\
\mathrm{n}=175\end{array}$ & & \\
\hline Type 1 & $13(10.5)$ & $0(0.00)$ & $13(7.4)$ & $\begin{array}{l}13(100.0) \\
(71.7-100)\end{array}$ & - \\
\hline Non-type 1 & $111(89.5)$ & $51(100.0)$ & $162(92.6)$ & - & $\begin{array}{c}51(31.5) \\
(24.5-39.3)\end{array}$ \\
\hline \multicolumn{6}{|l|}{ Predictive value } \\
\hline $\begin{array}{l}\text { PPV } \\
(95 \% \text { CI })\end{array}$ & $\begin{array}{r}13(10.5) \\
(5.9-17.6)\end{array}$ & - & - & - & - \\
\hline $\begin{array}{l}\text { NPV } \\
(95 \% \text { CI })\end{array}$ & - & $\begin{array}{l}51(100.0) \\
(91.2-100)\end{array}$ & - & - & - \\
\hline
\end{tabular}

NPV: negative predictive value, PPV: positive predictive value, ROP: retinopathy of prematurity

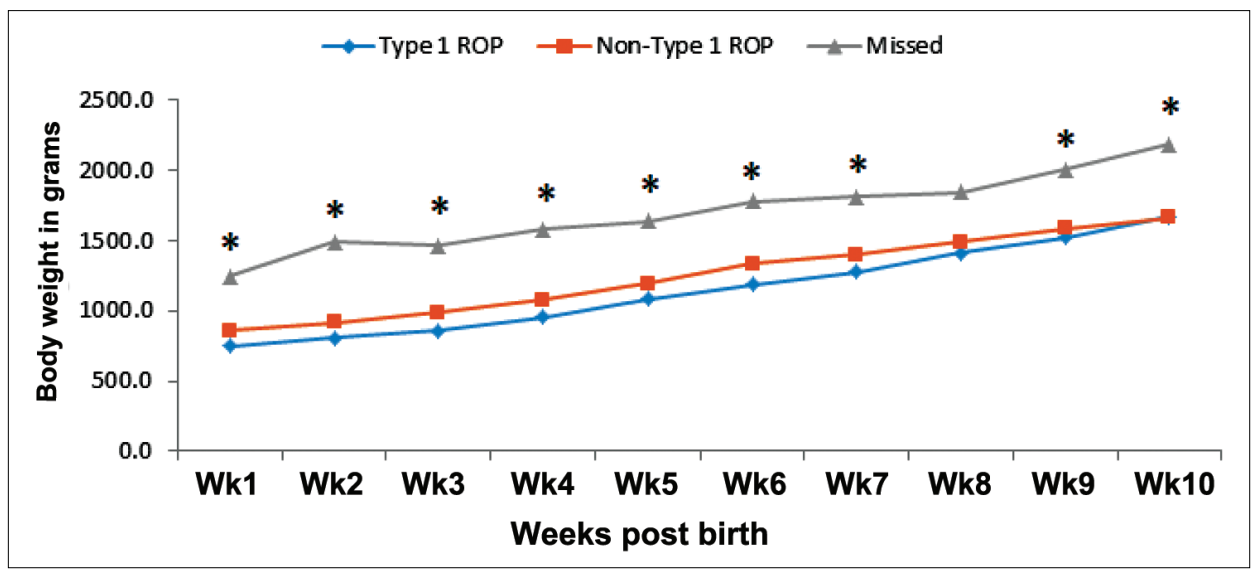

Figure 1 - Graph of the weekly bodyweight of the missed infants (triangles) who developed any stage of retinopathy of prematurity (ROP) in whom the WINROP algorithm did not signal a high-risk alarm with respect to other infants. Boxes represent the weekly weight of infants with non-type $1 \mathrm{ROP}$, and diamonds represent that of infants with type 1 ROP. The asterisks represent significant differences $(p<0.05)$.

infant's low serum IGF-1 and poor postnatal weight gain and the risk of developing more severe ROP., ${ }^{5,-23}$ Earlier studies from Sweden ${ }^{5}$ and North America, ${ }^{13}$ reported that all infants with stage 3 ROP were recognized by inserting only the postnasal weight measurements, further simplifying the WINROP system. Similarly, in this report of a Saudi cohort of premature infants, WINROP identified correctly all 13 infants (100\%) with type 1 ROP. This is what distinguishes our study from those conducted in other developing countries that showed lower sensitivity ranging from 80 to 90\%..$^{12,14-16,20,24-27}$ Sensitivity has also been demonstrated to be lower in heavier infants ( $>1000$ grams) in developed countries, which was not the case in our series. ${ }^{14}$

The overall specificity was low due to a high false-positive rate at $31.5 \%$. Largevariations in WINROP specificity have been reported in cross-sectional studies that validated the WINROP. ${ }^{8,10-12,14}$ Variability in cases, neonatal care, survival rates, and screening practices could all account for those discrepancies. However, since preventing retinal detachment and, ultimately, blindness is the goal of ROP screening, the sensitivity and NPV of ROP screening examinations are thought to be more relevant than its specificity.

This study validated the WINROP algorithm in a Saudi sample of preterm infants. It is novel in that it is 
the first study of this type conducted in a Middle Eastern cohort. WINROP may help clinicians determine whether infants are at risk for vision-threatening ROP. Given that this algorithm is completely based on weight measurements which are routinely documented in clinical practice worldwide, it is a non-invasive, useful adjunctive tool that can be used in addition to our national screening guidelines, which takes into account our geographic variabilities and local factors. Therefore, several attempts have been made to allow this tool to function optimally in developing countries. The NPV was $100 \%$, which is ideal to confidently reduce the ROP screening examination for infants with no alarm.

Study limitations. Firstly, one limitation is its retrospective design. The use of this algorithm, which is primarily designed for prospective use, may have affected the results. A multicenter prospective study including more premature infants will improve the value of the data. Secondly, there is a substantial subjective element in documentation and diagnosis of ophthalmoscopic findings. It was previously documented that the agreement on plus disease diagnosis among pediatric ophthalmologists is low. ${ }^{28-30}$ Thirdly, WINROP is not currently available for infants $\geq 32$ weeks of gestation. This has implications for our population, where older and heavier premature infants have been demonstrated to develop severe ROP in developing countries. ${ }^{31}$ Finally, our study is limited by small sample size. A study involving a larger number of infants is required to allow for regression analyses and to improve the accuracy of this screening tool.

In conclusion, this is the first report to document the use of a weight gain-based algorithm for the prediction of ROP from Saudi Arabia. The sensitivity of this algorithm in identifying type 1 ROP was $100 \%$, and specificity was $31.5 \%$. Our results are in line with those of previous reports that suggest using the WINROP algorithm to complement rather than substitute the current screening tools. As with any algorithm, researchers should consider customizing it taking into account the regional and demographic differences in premature newborns at risk of developing ROP.

Acknowledgment. We would like to thank Editage for English language editing services.

\section{References}

1. Isaza G, Aurora S. Incidence and severity of retinopathy of prematurity in extremely premature infants. J Can Ophtalmol 2012; 47: 296-300.

2. Bashinsky AL. Retinopathy of prematurity. N C Med J 2017; 78: 124-128.
3. American Academy of Pediatrics Section on Ophthalmology, American Academy of Ophthalmology, American Association for Pediatric Ophthalmology and Strabismus, American Association of Certified Orthoptists. Screening examination of premature infants for retinopathy of prematurity. Pediatrics 2013; 131: 189-195.

4. Tan JBC, Dunbar J, Hopper A, Wilson CG, Angeles DM. Differential effects of the retinopathy of prematurity exam on the physiology of premature infants. J Perinatol 2019; 39: 708-716.

5. Hellström A, Hård A-L, Engström E, Niklasson A, Andersson E, Smith L, et al. Early weight gain predicts retinopathy in preterm infants: New, simple, efficient approach to screening. Pediatrics 2009; 123: e638-e645.

6. Löfqvist C, Andersson E, Sigurdsson J, Engström E, Hård AL, Niklasson A, et al. Longitudinal postnatal weight and insulin-like growth factor i measurements in the prediction of retinopathy of prematurity. Arch Ophthalmol Chic Ill 1960 2006; 124: 1711-1718.

7. Winrop. winrop website. [cited 2020 Feb 4]. Available from: https://winrop.com/

8. Ali E, Al-Shafouri N, Hussain A, Baier RJ. Assessment of Winrop algorithm as screening tool for preterm infants in Manitoba to detect retinopathy of prematurity. Paediatr Child Health 2017; 22: 203-206.

9. Chaves-Samaniego MJ, Gómez Cabrera C, Chaves-Samaniego MC, Escudero Gómez J, García Campos JM, Muñoz Hoyos A, et al. Multicenter validation study of the Winrop algorithm as a method for detecting retinopathy of prematurity. J Matern Fetal Neonatal Med 2018; 19: 1-5.

10. Jagła M, Peterko A, Olesińska K, Szymońska I, Kwinta P. Prediction of severe retinopathy of prematurity using the Winrop algorithm in a cohort from Malopolska. A retrospective, single-center study. Dev Period Med 2017; 21: 336-343.

11. Jung JL, Wagner BD, McCourt EA, Palestine AG, Cerda A, $\mathrm{Cao} \mathrm{JH}$, et al. Validation of Winrop for detecting retinopathy of prematurity in a North American cohort of preterm infants. J AAPOS Off Publ Am Assoc Pediatr Ophthalmol Strabismus 2017; 21: 229-233.

12. Sanghi G, Narang A, Narula S, Dogra MR. Winrop algorithm for prediction of sight threatening retinopathy of prematurity: Initial experience in Indian preterm infants. Indian $J$ Ophthalmol 2018; 66: 110-113.

13. Wu C, Vanderveen DK, Hellström A, Löfqvist C, Smith LEH. Longitudinal postnatal weight measurements for the prediction of retinopathy of prematurity. Arch Ophthalmol Chic Ill 1960 2010; 128: 443-447.

14. Ko CH, Kuo HK, Chen CC, Chen FS, Chen YH, Huang $\mathrm{HC}$, et al. Using WINROP as an adjuvant screening tool for retinopathy of prematurity in Southern Taiwan. Am J Perinatol 2014; 30: 149-154.

15. Choi JH, Löfqvist C, Hellström A, Heo H. Efficacy of the Screening Algorithm WINROP in a Korean Population of Preterm Infants. JAMA Ophthalmol 2013; 131: 62.

16. Koçak N, Niyaz L, Ariturk N. Prediction of severe retinopathy of prematurity using the screening algorithm Winrop in preterm infants. J Am Assoc Pediatr Ophthalmol Strabismus 2016; 20 : 486-489.

17. Fierson WM, American Academy of Pediatrics Section on Ophthalmology, American Academy of Ophthalmology, American Association for Pediatric Ophthalmology and Strabismus, American Association of Certified Orthoptists. Screening examination of premature infants for retinopathy of prematurity. Pediatrics 2013; 131: 189-195. 
18. The International Classification of Retinopathy of Prematurity Revisited. Arch Ophthalmol 2005; 123: 991-999.

19. Good W, Hardy R, Dobson V, Palmer E, Phelps D, Quintos $\mathrm{M}$, et al. Revised indications for the treatment of retinopathy of prematurity: Results of the early treatment for retinopathy of prematurity randomized trial. Arch Ophthalmol 2003; 121 : 1684-1694.

20. Lundgren P, Stoltz Sjöström E, Domellöf M, Källen K, Holmström G, Hård AL, et al. Winrop identifies severe retinopathy of prematurity at an early stage in a nation-based cohort of extremely preterm infants. PloS One 2013; 8: e73256.

21. Jensen AK, Ying GS, Huang J, Quinn GE, Binenbaum G. Postnatal serum insulin-like growth factor I and retinopathy of prematurity. Retina 2017; 37: 867-872.

22. Binenbaum G, Tomlinson LA, de Alba Campomanes AG, Bell EF, Donohue P, Morrison D, et al. Validation of the postnatal growth and retinopathy of prematurity screening criteria. JAMA Ophthalmol 2020; 138: 31.

23. Löfqvist C, Hansen-Pupp I, Andersson E, Holm K, Smith LEH, Ley $\mathrm{D}$, et al. Validation of a new retinopathy of prematurity screening method monitoring longitudinal postnatal weight and insulinlike growth factor I. Arch Ophthalmol Chic Ill 1960 2009; 127: 622-627.

24. Wu C, Löfqvist C, Smith LEH, VanderVeen DK, Hellström A. Importance of early postnatal weight gain for normal retinal angiogenesis in very preterm infants. Arch Ophthalmol 2012; 130: 992-999.

25. Zepeda-Romero LC, Hård A-L, Gomez-Ruiz LM, GutierrezPadilla JA, Angulo-Castellanos E, Barrera-de-Leon JC, et al. Prediction of retinopathy of prematurity using the screening algorithm Winrop in a Mexican population of preterm infants. Arch Ophthalmol Chic Ill 1960 2012; 130: 720-723.
26. Sun H, Kang W, Cheng X, Chen C, Xiong H, Guo J, et al. The use of the WINROP screening algorithm for the prediction of retinopathy of prematurity in a Chinese population. Neonatology 2013; 104: 127-132.

27. Piyasena C, Dhaliwal C, Russell H, Hellstrom A, Löfqvist C, Stenson BJ, et al. Prediction of Severe Retinopathy of Prematurity Using the Winrop Algorithm in a Birth Cohort in South East Scotland. Arch Dis Child - Fetal Neonatal Ed 2014; 99: F29-F33.

28. Quinn GE, Ells A, Capone A, Hubbard GB, Daniel E, Hildebrand PL, et al. Analysis of discrepancy between diagnostic clinical examination findings and corresponding evaluation of digital images in the telemedicine approaches to evaluating acute-phase retinopathy of prematurity study. JAMA Ophthalmol 2016; 134: 1263-1270.

29. Campbell JP, Kalpathy-Cramer J, Erdogmus D, Tian P, Kedarisetti D, Moleta C, et al. Plus disease in retinopathy of prematurity: A continuous spectrum of vascular abnormality as a basis of diagnostic variability. Ophthalmology 2016; 123: 2338-2344.

30. Kalpathy-Cramer J, Campbell JP, Erdogmus D, Tian P, Kedarisetti D, Moleta C, et al. Plus disease in retinopathy of prematurity: Improving diagnosis by ranking disease severity and using quantitative image analysis. Ophthalmology 2016; 123: 2345-2351.

31. Quinn G. Retinopathy of prematurity blindness worldwide: phenotypes in the third epidemic. Eye Brain 2016; 8: 31-36. 